\title{
Is Aichi Target 11 Progress correctly measured for developing Countries?
}

Pierre Failler ${ }^{1}$, Grégoire Touron-Gardic ${ }^{1 *}$ and Marie-Suzanne Traore ${ }^{2}$

${ }^{1}$ Blue Governance Research Group, Faculty of Economics and Law, University of Portsmouth, Portsmouth, P01 3DE, United Kingdom.

${ }^{2}$ General Secretariat, Marine Protected Areas Network of West Africa (RAMPAO), Dakar, Sacred Heart 3 , Senegal.

*Corresponding author: gregoire.touron-gardic@port.ac.uk

\section{Keywords}

Aichi Target 11, World Protected Area Database, WDPA, Developing countries, West Africa, MPA

\section{Abstract}

Developing countries are struggling to meet Aichi Target 11, which calls for $10 \%$ of national marine area under protection. In addition, the official tool to measure their progress, the WDPA, tends to overestimate it. To reach this target, developing countries must set up large offshore Marine protected areas.

\section{Main Body}

Aichi Target 11, defined at the sixth meeting of the Conference of the Parties signatories of the Convention on Biological Diversity (CBD), states that by 2020, $10 \%$ of the coastal and marine areas of the signatory countries will be officially protected. Progress is recorded in the World Database on Protected Areas (WDPA) ${ }^{1}$, which is the reference instrument [1]. Under this basis, Marine Protected Areas (MPAs) cover 17.3\%, on average, of the Exclusive Economic Zones (EEZs) of coastal countries [2]. The progress towards Aichi Target 11, however, is very disparate among countries based on national income. $40 \%$ of high-income countries already exceed the $10 \%$ aim of protected national marine surface area, with $>50 \%$ above $5 \%$ protected area ${ }^{1}$. Contrastingly, of the 55 low to medium-low income coastal countries ${ }^{2}$, only 4 reached these $10 \%$. For another 40 countries, nearly $75 \%$ of the total, the level of achievement is less than $2 \%$ (Figure 1).

\footnotetext{
${ }^{1}$ See: www.Protectedplanet.net

${ }^{2}$ Following the World Bank classification: https://datahelpdesk.worldbank.org/knowledgebase/articles/906519-world-bank-country-and-lending-groups and the Gross national income (GNI) per capita list : https://data.worldbank.org/indicator/NY.GNP.PCAP.CD
} 


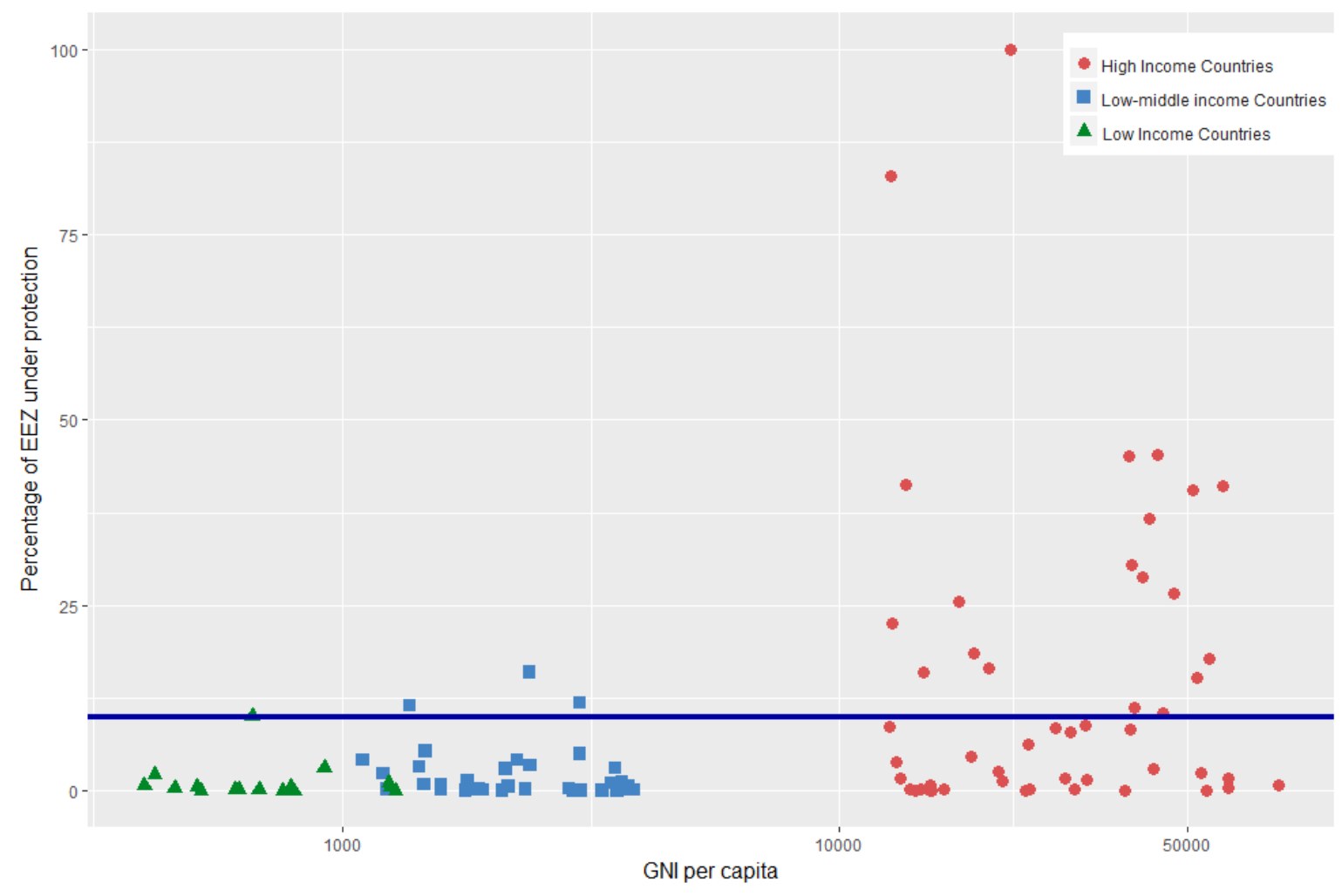

Figure 1 : Distribution of the countries with low, medium-low and high income as per proportion of protected marine area within their EEZ (Aichi Target 11 imposing 10\% of national protected marine area; blue horizontal line). Sources: Gross national income (GNI) per capita and countries classification: latest update from World Bank (only countries whose GNI per capita was calculated by World Bank between 2011-2017 are shown in the figure); Marine protected area surface: latest update from WDPA (2019). Note: the horizontal axis is a log2 scale.

The poor coverage of protected marine areas in low and medium-low income countries reflects the context in which conservation is implemented in these countries: institutions are too weak to meet their international commitments [3] while economic development is the main public policy concern [4]. In addition, the lack of funding and the political instability in some countries are adding to the difficulties of implementing measures to protect the environment [5].

Worryingly, the situation for low and medium-low income countries may be actually worse. The actual percentage of marine area protected in these countries is often overestimated in the WDPA ${ }^{3}$ [6], [7]. This situation arises first and foremost due to the quality of the data provided by the national institutions in charge of MPAs. The lower the income of a country, the more likely its institutions will provide incomplete, erroneous or obsolete data [8], [9]. A second source of error comes from potential double counting in the reporting process to the WDPA: when an MPA has several statuses, national status and RAMSAR labeling, for example, the area can be counted more than once (this is the case for several MPAs in Guinea-Bissau, which cumulatively include the status of "Natural Park", "National Park" or RAMSAR site) [10]. A third bias arises from the integration of areas whose low protection status or status indicating that the MPA has not been set up yet does not justify taking them into account for reaching Aichi Target 11, such as classified forests, areas of use regulated, proposed MPAs,

\footnotetext{
${ }^{3}$ Overestimation also affect high-income countries. Thus, it states that Slovenia has a protected marine area that is larger than its EEZ (see: https://www.protectedplanet.net/country/SI).
} 
which seems to be a recurring fact [8], [11]. Finally, an additional potential source of error is introduced by the WDPA. This happens when it does not have the outline of a protected site and considers its bounds as a regular circle ${ }^{1}$ (low and middle-low income countries have transmitted on average $25.2 \%$ of their PAs without contour, compared to $8,8 \%$ for high income countries). In the case of Mauritania, although their actual contours are not of this form, $56 \%$ of protected areas in the country are represented by points, including several coastal MPAs. When these sites are located at the interface between land and sea, it becomes impossible to obtain an accurate measurement of the marine surface. At last, data verifications are minimal since the WDPA consider that the data have been previously verified by the countries. Despite the fact that countries are responsible for the verifications, low and middle-low income countries rarely communicate about possible errors contained in the WDPA.

An examination of the situation of West African countries, ranging from Mauritania in the north to Sierra Leone in the south ${ }^{4}$, illustrates perfectly the potential error from repeated counting due to a site having multiple designated statuses. In 2018, an assessment of protected areas composing of the regional network of MPAs in West Africa (RAMPAO) was completed. This collaboration with the national administrations provided the most complete and exhaustive cartography of the region, specifying the surfaces of protected marine and terrestrial areas (see Figure 2 ) $^{5}$.

The total marine area obtained from the assessment is $14,424 \mathrm{~km}^{2}$ against $20,382 \mathrm{~km}^{2}$ in the WPDA. The marine protected area for seven West African countries in the WDPA is therefore overrepresented by nearly $30 \%$. Furthermore, of the 88 MPAs listed in the 2018 assessment, 54 are not included in the WDPA $^{6}$. In other words, the WDPA records about $40 \%$ of the legally existing MPAs while their total surface is about $30 \%$ overestimated. Other inaccuracies can be found in the WDPA in the use of MPA surface (the Gundjur / Fenyo Bolong Reserve in the Gambia has, for example, a correct outline in the WDPA but the indicated area does not correspond to that officially recognized) as well as in the digitization of their outlines (the Diawling National Park has a wrong outline in the WDPA although its area is well referenced). Consequently, Guinea Bissau, which was the only low-income country to reach Aichi Target 11 in Figure 1, would in fact only have $2.15 \%$ of its national marine surface under protection. Mauritania would be at $3.71 \%$, Senegal at $1.61 \%$ while other countries would be below $1 \%$. In Guinea-Bissau, the double-counting of some protected areas provides the most important source of surface error followed by the counting of two "not implemented yet" MPAs. Overall, the obsolete modeling of the coastline by the WDPA is a minor source of error ${ }^{7}$ compare to the erroneous contours and the arbitrarily modeled contours that introduce an important bias. The qualitative aspect has also to be considered as more than 30 West African MPAs were not recorder in the WPDA. As such errors

\footnotetext{
${ }^{4}$ Mauritania, Senegal, Cabo Verde, Gambia, Guinea-Bissau, Guinea and Sierra Leone.

${ }^{5}$ The coastline used comes from the most recent work (2018) of the Marine Flanders Institute. The coastline used by the WDPA is an older version (2014) of the work of the same Institute.

${ }^{6}$ The WDPA also contains two sites in Guinea-Bissau, Varela and Rio Grande in Buba, which were not included in this work due to their absence in the reference documents of the Institute for Biodiversity and Protected Areas in Guinea-Bissau (IBAP) and whose executives did not mention it.
}

\footnotetext{
${ }^{7}$ However, GIS data used by the WDPA contain other errors such as EEZ outlines. For example, Mauritania's EEZ in WDPA is measured at 156,198 $\mathrm{km}^{2}$ (using Flanders Marine Institute's data from 2014), while more recent data from Flanders Marine Institute consider that this EEZ is $173728 \mathrm{~km}^{2}$.
} 
have been identified for these seven West African coastal countries, they almost certainly exist for other low-income countries in Africa and other parts of the world [12].

Notwithstanding the issues with misreporting of protected areas, there needs to be a shift in how the protected areas are designated. Since the beginning of the 2010s, West African coastal countries have been implementing many small MPAs along the coastline with limited extension further out to sea. However, pursuing such close-to-shore initiatives would not be enough to reach the area imposed by Aichi Target 11. In this context, the use of large offshore MPAs has to be considered [13], [14]. These large MPAs should include underwater canyons and shoals with the highest biodiversity and including breeding or migration areas of fish and cetaceans (Figure 2).

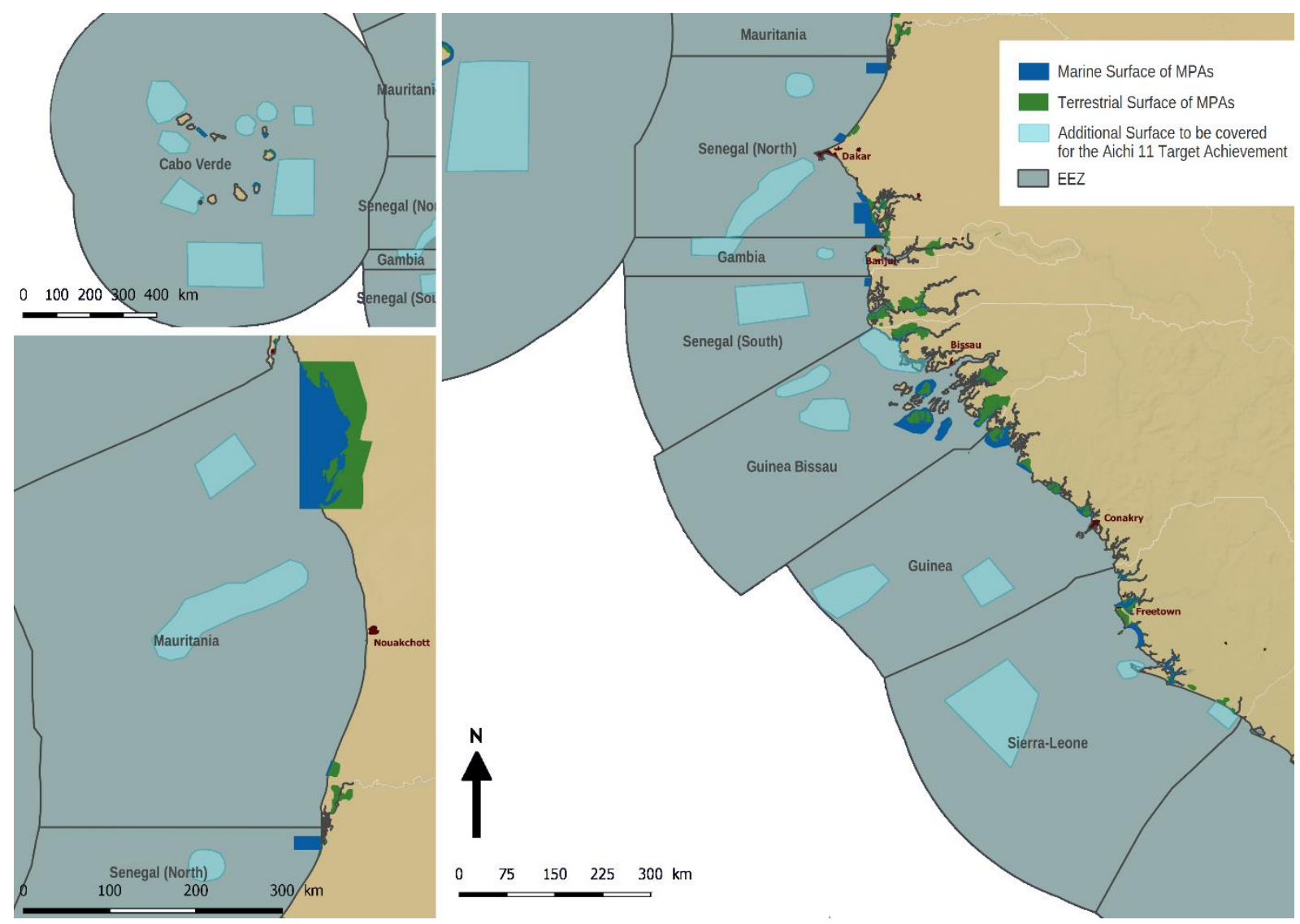

Figure 2: Contours of current MPAs (dark blue and green) and sites of high habitat and biodiversity that are prime candidates for MPAs, which cumulatively would meet the 10\% coverage for Aichi Target 11. Source: Own realization.

The creation of offshore MPAs, however, creates conflicts of interest and faces administrative and financial obstructions [15]. The development objectives of these countries currently focus on the exploitation of oil, gas and fisheries resources, notably by granting concessions (drilling) and access rights (fishing) to foreign companies, and these are contradictory to the protection of biodiversity. The same applies to all coastal countries of Africa and other continents that rely heavily on the growth of the blue economy to ensure their economic emancipation [4].

In conclusion, the progress towards Aichi Target 11 is poorly informed by the WDPA for some low- and middle-low income countries such as Guinea Bissau, whose surface is largely overestimated. In case of overestimation, these countries may be distracted from the Target. However, most of these countries are still far from the $10 \%$ protected marine area. A potential solution would be to adopt a new 
implementation strategy for establishment of offshore MPAs [13], [14]. However, this is a huge challenge given the institutional, human and financial deficit in the countries. Moreover, doing so is in contradiction with their current economic development strategies that are insufficiently in favour of environmental protection. Countries should receive substantial support for the maintenance and improvement of the health of coastal ecosystems, which makes a significant contribution to achieve the mitigation and adaptation goals set by countries.

\section{Acknowledgements}

We first of all offer our warm gratitude to Idriss Deffry, coordinator of the "Marine \& Coastal" regional thematic program of IUCN West and Central Africa. The latter made freely available the data he had gathered. We then thank all the managers of the MPAs as well as all the people in the administrations who have kindly provided the requested information.

\section{References}

[1] Smallhorn-west, P. and Govan, H. (2018) Towards reducing misrepresentation of national achievements in marine protected area targets. Mar. Policy 97, 127-129

[2] UNEP-WCMC, IUCN, and NGS (2018) Protected Planet Report 2018. Cambridge, UK

[3] UNDP (2018) Climate Change Adaptation in Africa - UNDP Synthesis of Experiences and Recommendations. Bangkok, Thailand

[4] World Bank and United Nations Department of Economics and Social Affairs (2017) THE POTENTIAL OF THE BLUE ECONOMY : Increasing Long-term Benefits of the Sustainable Use of Marine Resources for Small Island Developing States and Coastal Least Developed Countries. Washington DC, USA

[5] Amengual, J. and Alvarez-berastegui, D. (2018) A critical evaluation of the Aichi Biodiversity Target 11 and the Mediterranean MPA network, two years ahead of its deadline. Biol. Conserv. 225, 187-196

[6] Knowles, J. E. et al. (2015) Establishing a marine conservation baseline for the insular Caribbean. Mar. Policy 60, 84-97

[7] Thomas, H. L. et al. (2014) Evaluating official marine protected area coverage for Aichi Target 11 : appraising the data and methods that define our progress. Aquat. Conserv. Mar. Freshw. Ecosyst. 24, 8-23

[8] Han, X. et al. (2017) Monitoring national conservation progress with indicators derived from global and national datasets. Biol. Conserv. 213, 325-334

[9] Vanhove, M. et al. (2017) Joining science and policy in capacity development for monitoring progress towards the Aichi Biodiversity Targets in the global South. Ecol. Indic. 73, 694-697

[10] Spalding, M. D. et al. (2013) Protecting Marine Spaces: Global Targets and Changing Approaches in Dalhouse University, Ocean Yearbook 27, A. Chircop, Boston, USA, 213-248

[11] Sala, E. et al. (2018) Assessing real progress towards effective ocean protection. Mar. Policy 91, 11-13

[12] Visconti, P. (2013) Effects of Errors and Gaps in Spatial Data Sets on Assesment of Conservation Progress. Conserv. Biol. 27, 1000-1010 
[13] Doherty, T. S. et al. (2018) Expanding the Role of Targets in Conservation Policy. Trends Ecol. Evol. 33, 809-812

[14] Ban, N. C. et al. (2017) Social and ecological effectiveness of large marine protected areas. Glob. Environ. Chang. 43, 82-91

[15] Soares, M. O. and Lucas, C. C. (2019) Towards large and remote protected areas in the South Atlantic Ocean: St. Peter and St. Paul's archipelago and the Vitória-Trindade Seamount Chain. Mar. Policy 93, 101-103

\section{Supplementary Material}

Table 1: MPA counting in West African countries and comparison with WDPA

\begin{tabular}{|c|c|c|c|c|c|c|c|c|}
\hline & Mauritania & Senegal & $\begin{array}{l}\text { Cabo } \\
\text { Verde }\end{array}$ & Gambia & $\begin{array}{l}\text { Guinea- } \\
\text { Bissau }\end{array}$ & Guinea & $\begin{array}{l}\text { Sierra } \\
\text { Leone }\end{array}$ & Total \\
\hline $\begin{array}{l}\text { Number of officially } \\
\text { recognized MPAs }\end{array}$ & 5 & 24 & 29 & 8 & 6 & 6 & 10 & 88 \\
\hline $\begin{array}{l}\text { Number of MPAs in } \\
\text { WDPA }\end{array}$ & 4 & 14 & 4 & 8 & $8(-2)$ & 6 & 10 & 54 \\
\hline $\begin{array}{l}\text { Difference with } \\
\text { WDPA }\end{array}$ & 1 & 10 & 25 & 0 & -2 & 0 & 0 & $34(+2)$ \\
\hline $\begin{array}{l}\text { Total Surface of } \\
\text { officially recognized } \\
\text { MPAs [sq. } k m](1)\end{array}$ & 12,521 & 4,556 & 1,448 & 464 & 5,590 & 1,871 & 1,842 & 28,294 \\
\hline $\begin{array}{l}\text { Marine Surface of } \\
\text { officially recognized } \\
\text { MPAs [sq. } \mathrm{km}](2)\end{array}$ & 6,450 & 2,568 & 1,101 & 23 & 2,304 & 993 & 1008 & 14,447 \\
\hline $\begin{array}{l}\text { Surface of MPAs in } \\
\text { WDPA [sq. km] (3) }\end{array}$ & 6,488 & 1,766 & 5 & 16 & 10,661 & 583 & 863 & 20,382 \\
\hline $\begin{array}{l}\text { Difference between } \\
\text { (1) and (3) }\end{array}$ & 6,033 & 2,790 & 1,443 & 448 & $-5,071$ & 1,288 & 979 & 7,912 \\
\hline $\begin{array}{l}\text { Difference between } \\
\text { (2) and (3) }\end{array}$ & -38 & 802 & 1,096 & 7 & $-8,357$ & 410 & 145 & $-5,935$ \\
\hline $\begin{array}{l}\text { EEZ according to } \\
\text { Marine Flanders } \\
\text { Institute (2018) (sq. } \\
\text { km) }\end{array}$ & 173,728 & 158,936 & 804,694 & 23,184 & 107,301 & 102,587 & 161,275 & $1,531,705$ \\
\hline $\begin{array}{l}\text { EEZ contained in the } \\
\text { WDPA (Marine } \\
\text { Flanders Institute } \\
\text { 2014) (sq. km) }\end{array}$ & 156,198 & 158,426 & 801,065 & 22,746 & 106,507 & 110,136 & 160,453 & $1,515,531$ \\
\hline $\begin{array}{l}\text { Percentage of Marine } \\
\text { Area under protection } \\
\text { (WDPA 2019) }\end{array}$ & 4.15 & 1.11 & 0 & 0.07 & 10.01 & 0.53 & 0.54 & \\
\hline $\begin{array}{l}\text { Percentage of Marine } \\
\text { Area under protection } \\
\text { (data from officially } \\
\text { recognized MPAs and } \\
2018 \text { Marine Flanders } \\
\text { Institute's data) }\end{array}$ & 3.71 & 1.61 & 0.14 & 0.1 & 2.15 & 0.97 & 0.62 & \\
\hline
\end{tabular}

